\title{
Performance Analysis of the AODV Protocol over the ZigBee IEEE 802.15.4 Standard based on Different Traffics and Performance Metrics
}

\author{
Mehari Kiros \\ PhD scholar, \\ Andhra University College of Engineering (A), \\ Andhra Pradesh, \\ Visakhapatnam-530003, India
}

\author{
S. Pallam Setty, PhD \\ Professor \\ Andhra University College of Engineering (A), \\ Andhra Pradesh, \\ Visakhapatnam-530003, India
}

\begin{abstract}
As the demand in industry and academia for ubiquitous and pervasive computing increases, Wireless Sensor Network (WSN) becomes a popular research pool for the last decades. In this paper, it is presented that the performance analysis of the Ad hoc On-demand Distance Vector (AODV) protocol over the IEEE 802.15.4 standard (ZigBee) Wireless Sensor network in different scenarios. The performance analysis metrics used to simulate the AODV protocol for the ZigBee wireless Sensor Network are, energy consumption, average end to end delay, packet delivery ratio, load factor, jitter by varying the Constant Bit Rate (CBR), FTP and Poisson network traffics using the Network Simulator 2 which is commonly known as NS2 and it will be pointed out that on which traffic the protocol performs well and consumes less energy.
\end{abstract}

\section{General Terms}

Performance Metrics, Energy consumption, WSN

\section{Keywords}

WSN, sensor Nodes, AODV protocol, NS2, network traffic, ZigBee, IEEE 802.15.4

\section{INTRODUCTION}

The high demand of Wireless sensor Network in the industry and academia attracts the attention of researchers as well as consumers for the last decades and still deserving exponentially growing interest. The current advancements in low-power, low cost personal area network that is the Low Rate Wireless Personal Area Network (LR-WPAN) has created a pavement for Wireless Sensor network research scholars. The technology provides the technical sceneries to build a multifunctional tiny sensor device which gives a smart hand for environmental monitoring based on some set of physical parameters. These parameters are inputs to the sensors which can be industrial, from hazardous environments, natural and man-made environmental disasters. Wireless Sensor Network (WSN) becomes a research pool of the century due to the emergence of the so called Internet of Things (IOT). The application of WSN using the IEEE 802.15.4 standard ZigBee protocol is also becoming common in many fields of applications. The reactive protocol Ad hoc On-demand distance vector (AODV) is a choice to exploit the high flexibility of the application layer and which does not depend strictly on the MAC layer rules from the perspective of the routing techniques. The AODV protocol can also be extended to address many route selection metrics due to its flexibility and independency on the MAC layer. NS-2 is an event driven (discrete event) simulator developed as part of the VINT project at the University of California in Berkeley.
The project is funded by DARPA in collaboration with XEROX Palo Alto Research Center (PARC) and Lawrence Berkeley National Laboratory (LBNL) [14].

\section{RELATED WORKS}

In [3], a comprehensive study of two reactive routing protocols AODV and DSR is done for indoor and outdoor scenarios, it is found that AODV outperforms better than DSR in outdoor scenario with better end to end delay, packet delivery ratio and less packet loss. In [4], authors conducted a comparative study of AODV, DSR and DSDV based on packet delivery ratio and routing overhead by varying the number of source nodes, the simulation result shows that as the number of source nodes increases the routing overhead increases largely for AODV and DSDV routing protocols. In [5], performance analysis of AODV under black hole attack is conducted. Based on the packet delivery ratio, throughput, and energy consumption metrics, the proposed method slightly improves energy conservation. In [6], performance comparison of AODV and DYMO with respect to packet delivery ratio, end to end delay, and energy consumption in non-beacon enabled ZigBee network from the simulation result, it is inferred that performance of routing protocols mainly depends on size and density of the network. Authors of [7], the effect of communication radius in WSN mesh topology of ZigBee, increasing the ACTIVE_ROUTE_TIMEOUT value minimizes the energy consumption. The cross-layer sleep scheduling also enhances the performance and life time of the sensor nodes due to low duty-cycle [8]. Mesh topology affects the performance and life time of the sensor nodes due to high overhead and can be improved by reducing the route discovery of the routing protocols thereby enhances the scalability of the network $[9,10]$.

\section{THE ZIGBEE (IEEE 802.15.4) STANDARD}

The ZigBee technology is a newly emerging technology and devices based on the IEEE 802.15.4 are still need to be realized. The ZigBee devices are designed for low cost, low data rate and short range of personal area network. The IEEE 802.15 .4 standard is operated at $2.4 \mathrm{GHz}, 868$ and $912 \mathrm{MHz}$ frequency bands and $250 \mathrm{kbps}, 20 \mathrm{kbps}$ and $40 \mathrm{kbps}$ data rates respectively. The ZigBee network supports three types of network topologies: The star topology- the coordinator is a Full Functional Device (FFD) and others are Reduced Functional Devices (RFD) which is a one-hop network. The Mesh topology- allows the coordinators talk with other coordinators within their range and have communication capability of multi-hop routed to coordinators out of reach of their range. The mesh topology is suitable in applications 
where there is a need of large coverage area though the high overhead. The cluster tree topology is highly static and not suitable for most Wireless Sensor Network (WSN) deployment as the topology in WSN is most commonly dynamic [2].

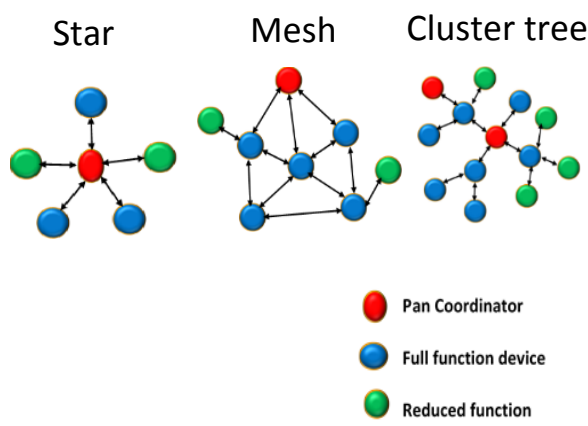

Fig.1. the Most common ZigBee topologies

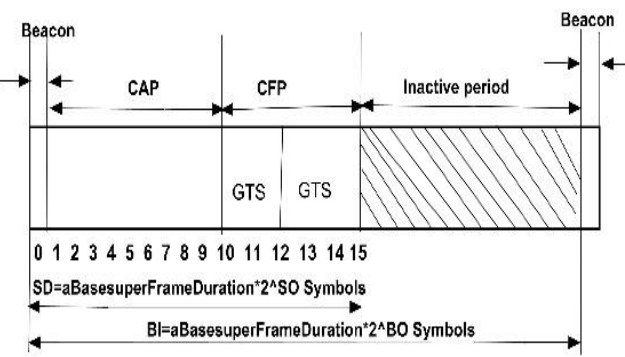

Fig.2. ZigBee (IEEE802.15.4) standard Super Frame structure

At the beginning, all the Pan-coordinators were generating beacon with the same intervals.

BO (Beacon order) is set to 3 by default for every fullfunctional device in the network.

$\mathrm{BI}($ Beacon Interval $)=$

aBasesuperframeduration $* 2^{\mathrm{BO}}$

aBase super frame duration $=\mathrm{aBase}$

slotduration*anumsuperframeslots

aBase slot duration $=60$ symbols

a number super frame slots $=16$

aBase super frame duration $=60 * 16$

aBase super frame duration $=960$

$\mathrm{BO}=3$

$\mathrm{BI}=960 * 2^{3}$ symbols

$\mathrm{BI}=7680$ symbols

$\mathrm{BI}=\mathrm{BI} / 250 \mathrm{~K}=7680 / 250000$

$\mathrm{BI}=30.72 \mathrm{msec}$.

These computations show that all pan-coordinators in the network are generating beacons after every $30.72 \mathrm{msec}$. BI (Beacon Interval) can be changed as per ones requirement by choosing different BO (Beacon Order) viz. 3, 4,5,6,7 and so on.

\section{ENERGY CONSUMPTION}

The LR-WPAN nodes are mostly battery operated WSN nodes and it is very difficult to replace or recharge the battery once deployed. Thus, energy is the most constrained parameter since it determines the life span of the WSN. Large amount of the energy of a WSN node is consumed by the radio module which is located at the physical layer of the layered protocol Stack of ZigBee when the node is in idle mode, receiving mode and transmitting mode. Therefore one can achieve energy conservation by employing energy aware routing protocols like the Ad hoc On-demand Distance Vector (AODV) that is the physical layer protocol by exploiting the frame filtering mechanisms [1] and changing the idle mode of nodes into sleep mode.

\section{PERFORMANCE EVALUATION METRICS}

Packet Delivery Function (PDF): It is the number of packets sent from the source to the number of packets received at the destination.

PDF $=$ (number of received packets/number of sent packets $) * 100$

End-to-End Delay (EED): It is the average time delay for data packets from the source node to the destination node. EED is measured as from PAN coordinator to RFD

$\mathrm{EED}=$ Recvedpkt time - sentpkt time

Where

Recvedpkt time $=$ Received Packet time

Sentpkt time $=$ Sent packet time

Average Energy Consumption (AEC): It is to compute the energy consumed by each wireless sensor node during transmission, reception, sensing and idle modes.

Energy Consumption $=\mathrm{Ei}-\mathrm{Ef}$

$\mathrm{AEC}=1 / \mathrm{N}\left(\sum \mathrm{Ei}_{\mathrm{i}}-\mathrm{Ef}_{\mathrm{i}}\right)$, for all $\mathrm{i}=1,2,3, \ldots, \mathrm{N}$

Where, Ei is Initial Energy of each node, Ef Final Energy left of each node, AEC stands for Average Energy Consumption and $\mathrm{N}$ represents the number of Sensor nodes in the network.

Jitter: is the variation in time between packets arriving, caused by network congestion.

Jitter $=$ Actual Transmission Time - Expected Transmission Time

Load Factor (LF): It is calculated as Packet rate divided by channel capacity.

$\mathrm{LF}=$ Packet rate/Channel Capacity

Channel Capacity = Data Rate/ Each Channel size

Packet rate $=($ Total packets Sent + Total packets receive $) /$ Simulation Time

Each channel capacity is $16 \mathrm{kbps}$ with data rate $250 \mathrm{kbps}$ and each packet is 20bytes. It is considered with constant Channel capacity with varying Packet Rate. 
Table1.Simulation Parameters

\begin{tabular}{|l|l|}
\hline Component & Type \\
\hline Routing protocol & AODV \\
\hline Antenna Model & OmniAntenna \\
\hline $\begin{array}{l}\text { Radio } \\
\text { Propagation } \\
\text { Model }\end{array}$ & TwoRayGround \\
\hline Initial Energy & 1joule \\
\hline $\begin{array}{l}\text { MAC layer } \\
\text { protocol }\end{array}$ & IEEE 802.15 .4 \\
\hline $\begin{array}{l}\text { Network } \\
\text { topology }\end{array}$ & Mesh topology \\
\hline $\begin{array}{l}\text { Network } \\
\text { interface type }\end{array}$ & $\begin{array}{l}\text { Phy/WirelessPhy/802.15 } \\
.4\end{array}$ \\
\hline $\begin{array}{l}\text { Interface queue } \\
\text { type }\end{array}$ & $\begin{array}{l}\text { Queue/DropTail/PriQue } \\
\text { ue }\end{array}$ \\
\hline Terrain area & $50 x 50 \mathrm{~m}^{2}$ \\
\hline Traffic type & FTP, CBR and Poisson \\
\hline Packet Size & 70 bytes \\
\hline Number of nodes & 25 \\
\hline Simulation time & 100 seconds \\
\hline
\end{tabular}

\section{SIMULATION RESULTS}

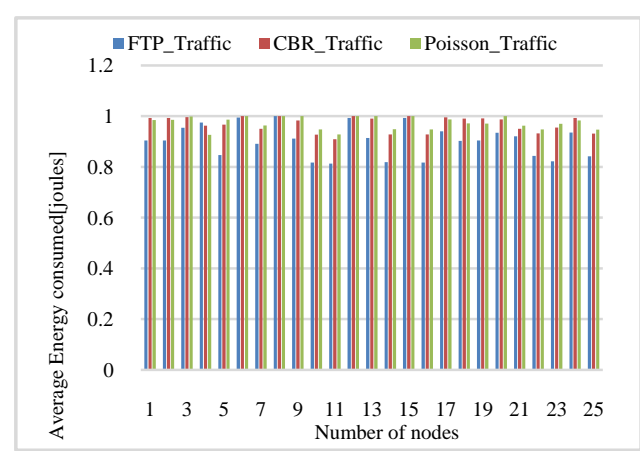

Fig. 3. Energy consumption of sensor nodes on different network traffics

Table 2. Summary of Simulation results

\begin{tabular}{|l|c|c|c|}
\hline $\begin{array}{c}\text { Traffics } \\
\text { Metrics }\end{array}$ & FTP & CBR & Poisson \\
\hline LF & 14.0032 & 3.9296 & 4.339 \\
\hline PDF (\%) & 89.273 & 74.431 & 97.093 \\
\hline EED(ms) & 0.0899 & 0.1634 & 0.01014 \\
\hline Jitter(ms) & 0.08614 & 0.16438 & 0.00995 \\
\hline AEC(J) & 0.9438 & 1.61026 & 1.0143 \\
\hline
\end{tabular}

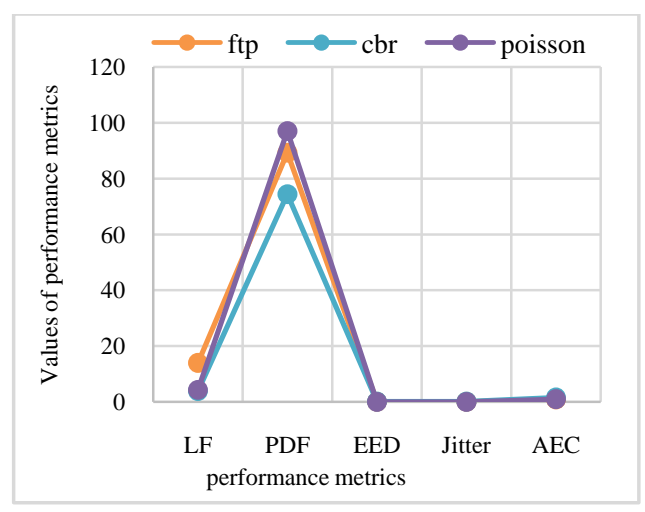

Fig. 4. Summary of the performance metrics

\section{CONCLUSION}

In this paper, the performance of FTP, CBR and Poisson network traffics with AODV protocol is evaluated. The simulation results show that energy consumption is high on Poisson and CBR traffics and somewhat lesser in the case of FTP traffic see Fig.3. As depicted in Fig.4. , packet delivery ratio (PDF) $97 \%, 89 \%$ and $74 \%$ in Poisson, FTP and CBR respectively. The jitter and End to End delay falls almost to zero in all traffic types. Hence, it can be inferred from Fig.3. , Fig.4. and Table 2 Poisson traffic can be used for delay and congestion critical applications, FTP can be applied for relatively longer life time nodes than Poisson and CBR, CBR traffic can be applied in areas where high jitter is not catastrophic. In future, the performance of the rest of the Wireless sensor network Routing Protocols will be addressed with all the three topologies with respect to energy conservation strategy.

\section{REFERENCES}

[1] Marwa Sharawi, Eid Emary, Imane Aly Saroit, Hesham El-MahdyWSN's Energy-Aware Coverage Preserving Optimization Model based on Multi-objective Bat Algorithm, 978-1-4799-7492-4/2015 IEEE.

[2] IEEE 802.15.4-2003 standard

[3] Hou Songfan, Wu Muqing, Liao Wenxing, Wang Dongyang, Performance Comparison of AODV and DSR in MANET Test-bed Based on Internet of Things, 978-14799-8091-8/2015 IEEE.

[4] Ganesh R. Pathak, Suhas H. Patil, Amar D. Rana, Yogendra N. Suralkar,Mathematical Model for Routing Protocol Performance in NS2:Comparing DSR, AODV and DSDV as Example, 2014 IEEE Global Conference on Wireless Computing and Networking (GCWCN).

[5] Hemant Sharma1,Koushik Banerjee2 and Brijesh Kumar Chaurasia ,Blackhole Tolerant Protocol for ZigBee Wireless Networks, 2014 Sixth International Conference on Computational Intelligence and Communication Networks.

[6] Adam Dahlstrom and Ramesh Rajagopalan, Performance Analysis of Routing Protocols in Zigbee Non-Beacon Enabled WSNs, 78-1-4673-3133-3/2013IEEE.

[7] Tao Weiye, Zeng Jieqiong, The Performance Study of ZigBee Mesh Network, 978-1-61284-486-2/2011IEEE.

[8] Barbara Staehle, Tobias Hoßfeld and Matthias Kuhnert, Norbert Vicari, A Cross-Layer Approach for Enabling Low DutyCycled ZigBee Mesh Sensor Networks, 978-14244-1653-0/2008 IEEE 
[9] Kwang Koog Lee, Seong Hoon Kim and Hong Seong Park, Cluster Label-based ZigBee Routing Protocol with High Scalability, Second International Conference on Systems and Networks Communications (ICSNC2007)IEEE.

[10] Kwang Koog Lee, Seong Hoon Kim, Yong Soon Choi and Hong Seong Park, A Mesh Routing Protocol using Cluster Label in the ZigBee Network, 1-4244-05076/2006 IEEE.

[11] Rubaina, avinder Singh Sawhney,Power Management and Reducing Routing Overhead and Delay in Wireless Sensor Network with Modified Adhoc on Demand Distance Vector Routing Protocol UsingThreshold Power, IJCA Volume 122 - No.12, July 2015.
[12] Myung J. Lee, Rui Zhang, Jianliang Zheng, Gahng-Seop Ahn, Chunhui Zhu, Tae Rim Park, Sung Rae Cho, Chang Sub Shin, and Jun Sun Ryu,IEEE 802.15.5 WPAN Mesh Standard-Low Rate Part: Meshing the Wireless Sensor Networks, IEEE JOURNAL ON SELECTED AREAS IN COMMUNICATIONS, VOL. 28, NO. 7, SEPTEMBER 2010

[13] Chunhui Zhu\#, Jianliang Zheng†, Chiu Ngo, Taerim Park*, Rui Zhang*, Myung Lee*,Low-Rate WPAN Mesh Network - An Enabling Technology for Ubiquitous Networks, This full text paper was peer reviewed at the direction of IEEE Communications Society subject matter experts for publication in the WCNC 2009 proceedings.

[14] The Network Simulator2- http://www.isi.edu/nsnam/ns 